\title{
CORRECTION
}

\section{Correction to: The Effect of Rifampin on the Pharmacokinetics and Safety of Lorlatinib: Results of a Phase One, Open-Label, Crossover Study in Healthy Participants}

\author{
Joseph Chen (1) - Huiping Xu $\cdot$ Sylvester Pawlak $\cdot$ Leonard P. James \\ Gerson Peltz $\cdot$ Kimberly Lee $\cdot$ Katherine Ginman • Michelle Bergeron • \\ Yazdi K. Pithavala
}

Published online: September 10, 2020

(c) Springer Healthcare Ltd., part of Springer Nature 2020

Correction to: Adv Ther (2020) 37:745-758

https://doi.org/10.1007/s12325-

019-01198-9

In the original article, the reference 4 has been published and cited incorrectly. The correct reference 4 is "Lorbrena ${ }^{\circledR}$ (lorlatinib) tablets. [Prescribing Information]. Pfizer Labs". Additionally, reference 4 was cited in error in the Discussion section of the original article (page

The original article can be found online at https://doi. org/10.1007/s12325-019-01198-9.

J. Chen $(\varangle) \cdot$ L. P. James

Global Product Development, Pfizer Oncology, New

York, NY, USA

e-mail: joseph.chen@pfizer.com

H. Xu . Y. K. Pithavala

Global Product Development, Clinical

Pharmacology, Pfizer Oncology, La Jolla, CA, USA

S. Pawlak

Global Product Development, Pfizer Inc., New

Haven, CT, USA

G. Peltz

Safety Surveillance and Risk Management, Pfizer

Oncology, Groton, CT, USA

K. Lee $\cdot$ M. Bergeron

Global Product Development, Pfizer Inc., Groton, CT, USA

K. Ginman

Global Product Development, Pfizer Inc., South

Lyon, MI, USA
755 , column 2, paragraph 2, sentence 1 ). The corrected sentence is as follows: "When used in drug-drug interaction studies to elicit metabolic induction, a rifampin dose of $600 \mathrm{mg} /$ day is typically not associated with transaminase elevations $[7,10] . "$ 